\title{
Cómo aprendió árabe Campomanes: sobre el aprendizaje de lenguas orientales en la Ilustración española*
}

\author{
How Campomanes Learned Arabic: On Learning \\ Oriental Languages in Spanish Enlightenment
}

\author{
Fernando Rodríguez-Mediano \\ Instituto de Lenguas y Culturas del Mediterráneo y Oriente Próximo, CSIC \\ ORCID iD: https://orcid.org/0000-0002-9432-6946
}

\begin{abstract}
Pedro Rodríguez Campomanes fue una de las figuras más destacadas de la Ilustración española. Uno de sus principales intereses fue el de la erudición arábiga. Conocemos su relación con proyectos institucionales, ligados, por ejemplo, a la Real Academia de la Historia, pero ignoramos cuál fue su relación directa con la lengua árabe, cómo la aprendió o cuál fue su conocimiento de la tradición orientalista. En este artículo estudio cómo aprendió árabe Campomanes, a partir de documentos de su archivo personal, y también de manuscritos de la Biblioteca Nacional de España pertenecientes a un colega de Campomanes, José Carbonel y Fogasa. Carbonel y Campomanes estudiaron juntos árabe con Miguel Casiri, y su documentación proporciona materiales de interés, no sólo para el aprendizaje del árabe y de otras lenguas extranjeras en el s. XVIII, sino en general sobre la historia del orientalismo europeo de esa época.
\end{abstract}

Pedro Rodríguez Campomanes, Count of Campomanes, was one of the most prominent figures of Spanish Enlightenment. One of his main intellectual interests was that of the Arabic erudition. We know many things about the great institutional projects in which Campomanes was involved, linked, for example, with his role as Director of the Real Academia de la Historia, but lesser is known about other aspects linked with his relationship with Arabic erudition: how did he learn Arabic, how much did he know about the Orientalist tradition... This paper studies how Campomanes learnt Arabic, throught the analysis of documents from his own personal archive, and other manuscripts from the Biblioteca Nacional de España regarding one of Campomanes' colleagues, José Carbonel y Fogasa. Campomanes and Carbonel studied Arabic with the maronite monk Miguel Casiri and their documents provide an unique material, not only for

* Este texto ha sido realizado gracias al proyecto «Orientalismo y verdad: la influencia de la erudición oriental en el desarrollo del pensamiento crítico en la España Moderna» (FFI2017-86538-P), IP's: Fernando Rodríguez Mediano y Mercedes García-Arenal.

Copyright: (C) 2020 CSIC. Este es un artículo de acceso abierto distribuido bajo los términos de la licencia de uso y distribución Creative Commons Reconocimiento 4.0 Internacional (CC BY 4.0). 
Palabras clave: Pedro Rodríguez Campomanes; Miguel Casiri; José Carbonel y Fogasa; Ilustración; orientalismo; aprendizaje del árabe; aprendizaje de lenguas extranjeras. the study of Arabic and other foreign languages in the 18th century, but also for the history of European Orientalism.

Key words: Pedro Rodríguez Campomanes; Miguel Casiri; José Carbonel y Fogasa; Enlightenment; Orientalism; Learning of Arabic; Learning of Foreign Languages.

Los estudios árabes fueron uno de los principales intereses eruditos de Pedro Rodríguez de Campomanes. Campomanes estudió árabe con el sacerdote maronita libanés Miguel Casiri y éste, a su vez, contó con el apoyo del jurista, ministro y académico asturiano para desarrollar su carrera en España. A partir de la relación entre Campomanes y Casiri se puede estudiar buena parte de la historia institucional del arabismo español del s. XVIII, dentro, por ejemplo, de la Real Academia de la Historia, de la que Casiri era miembro desde $1749^{1}$, y para la que llevó a cabo su trabajo sobre las monedas andalusíes².

Esta que he llamado «historia institucional» del arabismo español es más o menos conocida en algunos de sus rasgos y proyectos más característicos, como Bibliotheca de Casiri ${ }^{3}$, la traducción del Libro de agricultura de Ibn al- 'Awwām a cargo de José Antono Banqueri', o la Gramática $^{5}$ y el Diccionario ${ }^{6}$ árabes del padre Francisco Cañes; publicaciones todas en las que la influencia, apoyo y mecenazgo de Campomanes fue fundamental. Sin embargo, no sabemos qué significa exactamente la afirmación de que Campomanes estudió árabe. Dicho de otro modo, no sabemos con qué materiales y según qué método realizó ese aprendizaje, qué obras árabes utilizó, cómo ese estudio se integró en su proyecto historiográfico, $\mathrm{y}$, recíprocamente, de qué manera dicho proyecto se alimentaba de su erudición orientalista y era transformado por ella. El archivo de Campomanes contiene abundante documentación que aún debe ser estudiada con detalle para responder con

${ }^{1}$ Ladero Quesada, "Campomanes medievalista".

2 Martín Escudero, "El primer proyecto"; Martín Escudero, Las monedas de al-Andalus, especialmente "El arabismo en el siglo XVIII", pp. 34-44.

${ }^{3}$ Casiri, Bibliotheca arabico-hispana.

${ }^{4}$ Ibn al- 'Awwām, Libro de Agricultura. De manera general sobre Banqueri, Soto, Arabismo e ilustración; Labarta, "Banqueri y un anillo árabe".

${ }^{5}$ Cañes, Gramática.

${ }^{6}$ Cañes, Diccionario. Sobre Cañes, Moscoso, "El siglo XVIII español”. 
mayor precisión a estas cuestiones ${ }^{7}$. En este artículo voy a utilizar algunos de esos papeles producidos durante el aprendizaje del árabe de Campomanes, y también de su compañero José Carbonel y Fogasa, para responder a la pregunta de cómo aprendió árabe Campomanes. Para ello, y además de los papeles del Archivo de Campomanes en la Fundación Universitaria Española, voy a utilizar algunos materiales manuscritos que, aunque conocidos, no han sido todavía estudiados ni puestos en valor, como es el manuscrito 11554 de la BNE. El estudio de estos materiales quiere ser una aportación, en principio, al estudio de la historia del arabismo y del orientalismo español, pero puede significar también una aportación al tema más general del estudio de lenguas extranjeras en España.

\section{Los documentos de Campomanes}

Campomanes estudió árabe con Miguel Casiri, aunque nunca pudo dedicar a ese estudio el tiempo que requiere. En la relación de Casiri y Campomanes, los papeles de profesor y discípulo se intercambiaron con los de mecenas y protegido, estableciendo un vínculo que era a la vez amistoso, académico y clientelar. Se trata de una relación que contaba, además, con la presencia de al menos un tercer personaje, José Carbonel y Fogasa (o Fougasse), uno de los eruditos más interesantes, y quizás desconocidos, del s. XVIII español ${ }^{8}$. Carbonel fue académico de la Historia, profesor en la Academia de Guardias Marinas de Cádiz y secretario de la Asamblea Amistosa Literaria de Cádiz, bajo la dirección de Jorge Juan; actividades durante las cuales desplegó su interés por disciplinas variadas: lenguas clásicas y orientales, botánica, astronomía, numismática... Fue, también, el primer profesor de griego de Campomanes, en una fecha anterior a $1748^{9}$, y compartió con él los estudios de lengua árabe con Casiri entre 1748 y $1751^{10}$. De manera que, en compañía de Carbonel y Casiri, Campomanes se introdujo en el mundo de la erudición árabe y

${ }^{7}$ De parte de estos papeles ya había dado noticia, en primera instancia, Fernández, “Arabismo español”, esp. pp. 48-50.

${ }^{8}$ Die Maculet y Alberola Romá, "José Carbonel Fougasse".

${ }^{9}$ Gil Fernández, Campomanes, pp. 33-34.

${ }^{10}$ Gil Fernández, Campomanes, pp. 32-33. 
de la griega, como disciplinas integradas en un interés común por las antigüedades y las letras humanas ${ }^{11}$.

En el archivo de Campomanes, custodiado en la Fundación Universitaria Española, se conservan varios documentos producidos por su aprendizaje del árabe. Algunos de estos papeles tienen una forma fragmentaria y miscelánea, en el sentido de que están constituidos por notas gramaticales, pequeños glosarios, traducciones incompletas, prácticas de escritura o de ortografía... ejercicios, en fin, propios de un proceso del aprendizaje de una lengua. Así, por ejemplo, el documento titulado «Borradores de mis ejercitaciones para aprender el trabajo el Arábigo con el Sr. Casiri en compañía del Sr. Carbonel» ${ }^{12}$ incluye: una interpretación del alfabeto cúfico; varias hojas de una traducción parcial de un texto médico árabe (con anotaciones marginales sobre gramática o léxico); varios glosarios árabe-castellano y árabe-latín (por ejemplo, de preposiciones) en distintos grados de compleción; un alifato; diversas oraciones cristianas en árabe (el Ave María, el Padrenuestro, el Credo...); un fragmento de una gramática árabe en latín, más sistemática, con el título «Institutiones grammaticae arabicae», con pe-

\footnotetext{
${ }^{11}$ Para entender mejor el impulso intelectual y la visión que alimentaba este acercamiento erudito al aprendizaje de lenguas antiguas en este pequeño grupo se puede citar lo que escribía Pérez Bayer a Gregorio Mayáns sobre sus propios estudios apenas un par de años antes, en 1745: «Procedo no sé si diga lentamente o aprissa en el hebraísmo las horas pomeridianas las dos al francés por no perder lo que he podido recoger en mi viage. Espero que en este año 46 sabré el hebreo más que medianamente, digo para entender no sólo la Biblia, sino los libros rabbínicos y leer aquélla sin puntos. De S. Juan en adelante estudiaré por las tardes el griego pues para esse tiempo ya creo avré dexado el francés y me bastará hablar este o otro rato con algún inteligente en este idioma para conservar lo estudiado. El año 1747, si Dios me da vida, tengo ánimo de entregarme todo al griego y por las tardes al hebreo para conservar y aun adelantar algo. Si estas cuentas me salen bien puedo en estos dos años estar bastantemente versado en estas lenguas [...]. Ni me disgusta el pensamiento de los Orígenes [...] del Sr. Martí por cuya oferta doy a Vm. muchas gracias, pero ni por ahora puedo emprender esto pues estoy destituido de tiempo y facultades, esto es de los idiomas que son precissos para esta obra. La otra de las monedas (sobre que recaía el juizio de antaño) me agrada insignemente, pero estamos en lo mismo. Por ahora para descargo de mi conciencia y satisfacción de $\mathrm{Vm}$. le asseguro no pierdo tiempo. De aquí a dos años trataremos de ratione studiorum, no dudando yo que $\mathrm{Vm}$. me podrá aiudar y que me aiudará mucho. También creo que para lo de las monedas se necessitaría algo de Geographía, pero para lo de los Orígenes ciertamente se necessita saber arábigo, de suerte que si eligiesse yo esto último me sería precisso estudiar este idioma y empezaría luego, después del griego, no dudando que no solamente me serviría para los Orígenes sino para otras mil antiguallas y manuscritos arábigos». Pérez Bayer, "Carta a Gregorio Mayáns".

${ }^{12}$ Fundación Universitaria Española, Archivo de Campomanes (AC), 28-5.
} 
queños epígrafes dedicados al artículo, los pronombres y el verbo; distintas pruebas y ejercicios (por ejemplo, de la unión entre la preposición $b a^{\prime} d$ con los sufijos pronominales, conjugaciones o declinaciones), realizados en ocasiones con dos tintas para separar los distintos componentes de la palabra; varios dichos sapienciales en árabe; una lista de los nombres árabes del calendario gregoriano; un fragmento de traducción del tratado de Ibn al-Baytạ̄ ${ }^{13}$; varios diálogos, en árabe y castellano, que son ejercicios de redacción que incluyen temas más simples (los saludos, una invitación a comer) a otros más complejos (la diferencia entre países cristianos y países musulmanes). Además del título ya mencionado («Borrador...»), hay otro título en árabe, «Kitāb al-Butrus Rudrigis Kambūmānis. Bi-sm al-[A]b [sic] wa-l-Ibn wa-l-Rūh al-Qudus» («El libro de Pedro Rodríguez Campomanes. En el nombre del Padre, del Hijo y del Espíritu Santo»).

En otro bibliorato ${ }^{14}$ de papeles arábigos de Campomanes se incluyen: de nuevo, unas «Institutiones Grammaticae Arabicae», con epígrafes sobre el artículo, los casos, los pronombres y la conjugación verbal; diez composiciones a modo de ejercicios, en árabe y latín, con las traducciones árabes corregidas, probablemente por Casiri, y de tema principalmente religioso (por ejemplo, el texto latino de la primera de estas composiciones dice: «In nomine Domini qui fecit Coelum et terram, incipiamus in primi post invocationem divini auxilis, sub patrocinio Dominae nostrae Mariae virginis, eiusque Matris Sanctae Annae, componere aliquid in Lingua Arabica, juxta institutiones Grammaticae. Haec lingua est dificiliis, est necessaria illiis qui quaerunt scientias»; el de la segunda dice: «Amate ò discipuli virtutem quae vos facit gratos Deo, et charos hominibus in hac vita ac in altera. Componite benè et cavete ab erroribus, quapropter satagite, et studete regulis Grammaticae»); unos glosarios incompletos, en el sentido de que varias páginas contienen listas de palabras latinas a las que no siempre se ha añadido su correspondiente árabe; una lista de los pronombres árabes, en una hoja que contiene también unas notas sobre el Fuero de Sigüenza (en un caso de reutilización del papel); una versión de algunas de las composiciones citadas previamente; un pequeño fragmento del inicio árabe

${ }^{13}$ Sobre la fortuna de este texto en el s. XVIII español, Carrillo y Torres, Ibn al-Baytar, donde se cita el documento del que hablo, p. 38, n. 121.

${ }^{14} \mathrm{AC}, 28-4$. 
del libro Šams al-ma 'ārif de al-Būnī, con su correspondiente traducción castellana; más un par de hojas de apuntes, ejercicios, pruebas caligráficas... en árabe.

De esta brevísima descripción se puede entender el carácter misceláneo de unos documentos producidos por el aprendizaje de árabe de Campomanes, que en una primera instancia pueden ser clasificados en varios apartados: materiales de gramática árabe, en latín y castellano; glosarios y listas de palabras; oraciones cristianas en árabe; composiciones a modo de ejercicio, con tema religioso, pero también con dimensión práctica o etnográfica; diálogos; textos árabes traducidos.

La estructura de estos materiales puede entenderse mejor si se comparan con documentos del condiscípulo de Campomanes, José Carbonel y Fogasa, cuyos papeles arábigos están recogidos en un manuscrito de la Biblioteca Nacional, catalogado con el título de Papeles varios de gramática arábiga ${ }^{15}$. El siguiente apartado está dedicado a la descripción de este manuscrito.

\section{Los Papeles varios de gramática arábiga de José Carbonel}

Este manuscrito de Carbonel es un códice también misceláneo, donde están agrupados distintos cuadernos de contenido gramatical árabe. En el Apéndice Documental se puede encontrar una descripción más detallada del contenido de estos cuadernos, aunque aquí ofreceré unas consideraciones generales sobre el mismo.

Como explica en la primera página del códice, se trata de una «Gramática Árabe y Castellana, manuscrita original; por Don José Carbonel, Maestro que fue de varios ramos de ciencias de Su Excelencia, Padre de Vuestra Excelencia. Incluye también varios rasgos de literatura Árabe y Hebreo [sic] antiguo. Habiendo muerto en 1801 Don Joseph Carbonel en Cádiz, pasó esta obra a su hijo mayor, Don Antonio Carbonel, Bibliothecario Antiquario del Real Seminario de Nobles y Anticuario de los Reales Estudios de San Isidro; está actualmente jubilado de ambos establecimientos».

Como he dicho, se trata de un manuscrito misceláneo que contiene 12 cuadernos con diversos materiales relacionados con la lengua árabe.

${ }^{15}$ Carbonel, Papeles varios de gramática arábiga. Partes de este manuscrito y otros papeles de Carbonel han sido objeto de mi estudio "El perfil intelectual". 
Como se puede observar por la descripción incluida en el Apéndice Documental, hay en ellos apuntes gramaticales, glosarios, composiciones, diálogos, traducciones, modelos epistolares, interpretación de inscripciones epigráficas... Lo primero que se puede señalar de este manuscrito es su coincidencia con los documentos del archivo de Campomanes tratados en el apartado anterior. Así, por ejemplo, las primeras 10 composiciones árabes y latinas del cuaderno 2 son literalmente las mismas que las de Campomanes. Algunos de los glosarios del cuaderno 3 coinciden exactamente otros de Campomanes; esta coincidencia llega hasta el punto de que las palabras latinas para las que no consta equivalente árabe son las mismas en unos y otros papeles. Los primeros diálogos del cuaderno séptimo son los mismos. En el cuaderno 8, 10 son también el original árabe y la traducción castellana de la carta de recomendación escrita por un Miguel a un mercader de Alepo llamado Joseph (Yūsuf) para presentarle a un tal Jaime (o Ya 'qūb), que va a viajar a Siria. Los papeles de Carbonel también contienen un fragmento de traducción castellana y latina del libro de al-Būnī, además de un pequeño glosario producido en el curso de la traducción; aunque ambas traducciones, la de Carbonel y la de Campomanes, no son iguales, sí son producto de un mismo ejercicio. Estas coincidencias, que llegan a un gran nivel de detalle, permiten poner en relación ambos fondos, al menos en lo que concierne al momento inicial del aprendizaje de ambos. El manuscrito de Carbonel, sin embargo, muestra una mayor sistematización, además de añadidos posteriores a ese momento.

Una segunda observación de estos papeles se refiere a su carácter misceláneo: los diálogos, gramáticas, glosarios especializados, fórmulas de tratamiento, ejercicios y diálogos, textos religiosos, textos literarios, editados y traducidos etc., nos permiten pensar el estudio del árabe, no sólo como un aprendizaje lingüístico, sino como una forma de participación en una tradición intelectual, que construye un conocimiento sobre una lengua al mismo tiempo que elabora un canon literario y cultural de la misma. Es decir: el proceso de aprendizaje de la lengua árabe (y no sólo) es inseparable del de la construcción de un sistema de representación de la cultura árabe en Europa.

Una muestra de la intricación de ambos elementos (aprendizaje y representación) en un solo proceso de notable densidad lo proporciona el caso Johann Fabricius Dantiscanus, cuyo Specimen arabicus es citado en el Cuaderno 10 del manuscrito de Carbonel. Esta obra es una cresto- 
matía compuesta por un discípulo de Jacob Golius, y constituye uno de los hitos a través de los cuales la poesía árabe se difundió por la Europa del s. XVII, partiendo del principio de que los textos literarios eran un material necesario para aprender el árabe ${ }^{16}$. Las circunstancias de su composición hablan de la complejidad de un proceso académico e intelectual que implicaba a una parte importante de la República de las Letras del s. XVII. Como ha estudiado Jan Loop ${ }^{17}$, Fabricius había obtenido la mayor parte de los materiales para su libro cuando fue discípulo de Jacob Golius, el gran orientalista de Leiden. De hecho, el propio Golius editó parte de esos mismos materiales más tarde, en 1656. Como señala el propio título de la obra, se trata de una edición realizada por Golius de la pionera gramática de su maestro Thomas Erpenius, con el añadido de unos textos. Entre estos están las Fábulas de Luqmān, una colección de sentencias y adagios en árabe («initium sapientiae est timor», «eruditus in patria sua est ut aurum in fodina sua»...), la maqāma primera de al-Harīīī y una casida de Abū l- 'Alā' al-Ma 'arrī' es decir, dos de los textos editados y traducidos por Johann Fabricius Dantiscanus en el Specimen arabicum y copiados por Carbonel. De forma que, cuando éste cita a Fabricius, en realidad nos está indicando su pertenencia a una larga tradición erudita y orientalista que se remonta al menos al s. XVII, y que reunía a la vez materiales gramaticales, poéticos, literarios, sapienciales, religiosos, recogidos y aquilatados en el proceso de construcción del orientalismo moderno, en una práctica que funciona a escala continental.

Que Campomanes tenía una idea clara de esta tradición se muestra en el «Discurso preliminar...» al Diccionario de Francisco Cañes ${ }^{18}$, donde habla de cómo los árabes «habían sido también diligentes en tratar de la gramática de su lengua, compilación de diccionarios, y en cultivar la poesía; debiéndose a ellos la rima o consonancia», citando para demostrarlo los materiales utilizados por Edward Pococke en su Scientia metrica et rhytmica ${ }^{19}$, uno de los primeros tratados de métrica árabe

\footnotetext{
${ }^{16}$ Hasta donde conozco, el único estudio reciente sobre Johann Fabricius se encuentra en Loop, “Arabic Poetry", pp. 237-243.

17 Además del texto citado, v. Loop, Johann Heinrich Hottinger, pp. 173-174.

${ }_{18}$ Moscoso, "El siglo XVIII español".

${ }^{19}$ Se trata en realidad de una obra doble, que contiene la edición árabe, traducción latina y comentarios de Edward Pocoke sobre la Lämiyyat al- 'aŷam de al-Ṭugrā'̄ (al-Ṭgrā'̀ Làmiyyat), publicada junto con el ensayo del discípulo de Pocoke Samuel Clarke, Scientia metrica.
} 
en Europa ${ }^{20}$, y del que Campomanes decía que «no es común» ${ }^{21}$. En su «Discurso», Campomanes pasa revista, tanto a «las tentativas hechas en España en los tres últimos siglos para el uso para el uso etimológico e inteligencia del árabe», como a «los diccionarios árabes publicados en el presente y anterior siglo» ${ }^{22}$ (Rodríguez Campomanes, 1787: XVI y XX). En esta sección, entre otras cosas, hace una lista de algunos de los diccionarios árabes publicados en Europa desde el siglo XVII, los de Raphelengius (1613), Giggeo (1632), Germán de Silesia (1639), Golius (1653) (el mejor de todos ellos, según Campomanes), Meninski (1680) y, finalmente, el de Johannes Willmet (1784) ${ }^{23}$.

Por su parte, Cañes, en la introducción a su Gramática, cita las principales gramáticas que había utilizado para preparar la suya: Pedro de Alcalá (1506), Thomas Erpenius (1613, aunque con muchas reimpresiones), Filippo Guadagnoli (1642), Antonio dell'Aquila (1650), Agapito a Valle Flemmarum (1687) y la gramática de un Fr. Francisco González, seguramente una alusión a la Gramática de Bernardino González, que Cañes conocía perfectamente ${ }^{24}$. En estas dos listas de gramáticas y diccionarios están recogidas algunas de las obras más importantes de esa tradición gramatical y lexicográfica producida por el orientalismo europeo del s. XVII, cuyos dos hitos fundamentales son, respectivamente, la Gramática de Erpenius y el Léxico de Golius ${ }^{25}$.

Para explicar cómo los documentos de Carbonel y Campomanes se insertan en esta tradición gramatical orientalista se podría abordar el problema de la tensión entre el uso de categorías latinas para estudiar el árabe, como había hecho Erpenius, o la adopción de categorías propias de la rica tradición gramatical árabe; una tensión que atraviesa el orientalismo europeo y que llega, desde luego, al s. XVIII español ${ }^{26}$. Es éste un problema que tiene que ver con la cuestión de cómo los saberes occidentales, entre ellos la gramática, se transforman a partir de

${ }^{20}$ Gallien, "Orientalist Pococke". Sobre Pococke, Holt, "An Oxford Arabist".

${ }^{21}$ Campomanes, "Discurso preliminar", p. xi.

${ }^{22}$ Campomanes, "Discurso preliminar", p. xvi y xx.

${ }^{23}$ Moscoso, "El siglo XVIII", p. 172.

${ }^{24}$ Lourido, "Estudio preliminar".

${ }^{25}$ Girard, "Les manuels".

${ }^{26}$ Un análisis ejemplar de este tipo, y que atañe a la Gramática de Cañes, en Zwartjes, "Inflection and Government". 
la expansión imperial de época moderna. Durante este proceso, se acentúa la divergencia entre distintos métodos de aprendizaje de lenguas, más centrados en la normativa gramatical o en la práctica conversacional, en la teoría o en la traducción ${ }^{27}$, de forma que los materiales de aprendizaje lingüístico parecen responder a la realidad polifacética de la expansión imperial y sus exigencias de comunicación y aprehensión cultural. El estilo de los diálogos, por ejemplo, fluctúa entre el respeto a las reglas del género y la necesidad de recrear las condiciones reales de la comunicación hablada.

Por supuesto, en este proceso de creación gramatical desempeña un papel central el problema de la evangelización ${ }^{28}$ : en estas gramáticas árabes, la tensión entre un árabe musulmán y un árabe cristiano se hace siempre evidente, siquiera por la reproducción constante de oraciones y textos cristianos. No se trata de una característica exclusiva de los manuales de árabe, pues es habitual también en los de otras lenguas. Sin embargo, en el caso del árabe y su vínculo con el islam, esta característica no deja de ser especialmente significativa. En el desarrollo del orientalismo europeo moderno, fue determinante la presencia de árabes cristianos orientales como Ecchelensis, Assemani o el propio Casiri. Más allá de los discursos sobre la utilidad científica del árabe que se pueden encontrar en los textos ilustrados, para Casiri el trabajo más importante de su carrera de arabista había sido, no el monumental catálogo de manuscritos del Escorial, sino el que dedicó al manuscrito de cánones árabes de la iglesia hispana, hoy en la Biblioteca Nacional, al que consideraba «el monumento más auténtico que tiene la Iglesia de España, y aun la universal, para provar la tradición y el dogma», cuya edición y traducción «apoyaría la religión cathólica en gran parte, avergonzaría a los novadores del siglo $16 »^{29}$. Esta frase hace evidente la pulsión religiosa e identitaria que animaba en parte el proyecto de Casiri, que se puede rastrear en la historia de un orientalismo europeo siempre preocupado con los textos del cristianismo árabe, y que no es directamente identificable con el utilitario discurso ilustrado. No se puede olvidar que el tema de los mozárabes interesó al mismo Campomanes, como muestra un ensayo que dedicó a los «Muzárabes. Ob-

27 Zwartjies, "Métodos de enseñanza".

${ }^{28}$ Girard, "Les manuels"; Moscoso, "El s. XVIII".

${ }^{29}$ García-Arenal y Rodríguez Mediano, "Los libros de los moriscos”, p. 641. 
servaciones sobre la inteligencia de esta voz y libre exercicio de la religión christiana de los españoles en las provincias dominadas por los Mahometanos, formadas por el Señor Campomanes $\rangle^{30}$.

Esta cita de Campomanes nos conduce ya de lleno a sus intereses históricos y eruditos. Estos están ya anunciados desde el mismo momento en que empezó a estudiar árabe, y están plasmados, por ejemplo, en los primeros intentos de descifrar las inscripciones andalusíes. El propio Carbonel explica, en el Documento 4 de su manuscrito, cómo empezó ese proyecto:

Creo que la $1^{\text {a }}$ inscripción Arábigo-Cúfica que se logró descifrar en España fue la que se encontró en Tortosa, año de 1747, y se remitió a la Real Academia de la Historia, quien me encargó su interpretación. Sus caracteres, de puro adornados, parecían un bordado de capricho más bien que letras o geroglíficos. Sin embargo, tuve la fortuna de leer el $1^{\text {er }}$ renglón y la $1^{\mathrm{a}}$ palabra del $2^{\mathrm{do}}$, aunque confieso debí este acierto a la casualidad de haber visto antes algunas monedas Árabes, cuyos caracteres son substancialmente del mismo sistema de escritura que los de esta inscripción, pero sin adorno alguno. Yo la hubiera leído toda, a no ser tan principiante en la Lengua Arábiga. Lo executó por mí el $\mathrm{S}^{\mathrm{r}} \mathrm{D}^{\mathrm{n}}$ Miguel Casiri, mi maestro en aquel idioma, y sumamente hábil en él, y en el Siriaco y Caldeo.

De nuevo, este documento de Carbonel puede ponerse en relación con los documentos de Campomanes, entre los que se encuentra una interpretación del alfabeto cúfico, con la equivalencia de sus caracteres con los del alifato común ${ }^{31}$. Sabemos que en la documentación de la Real Academia de la Historia se conserva el informe más antiguo realizado sobre inscripciones árabes, escrito por el propio Campomanes en 1752; en él se menciona un informe previo realizado por Casiri sobre la inscripción de Tortosa, presentado a la Academia el 25 de octubre de 1748 , aunque hoy se considera perdido ${ }^{32}$. Este desciframiento de la inscripción de Tortosa sería el comienzo de un largo proyecto de catalogación y sistematización de la epigrafía árabe llevado a cabo por la Real Academia de la Historia. Así, el alifato en cúfico que se encuentra entre los papeles de Campomanes sería uno de los primeros, quizás el primer, testimonios documentales de ese trabajo, que hay que poner en relación con otros papeles del mismo archivo («Translatio caracterum cuficorum in caracteres arabicos orientales cum suis punctis $\left.»^{33}\right)$. Otra

${ }^{30} \mathrm{AC}, 16-23$.

${ }^{31} \mathrm{AC}, 28-5$.

${ }^{32}$ Martínez Núñez, Epigrafia árabe, pp. 27-28.

${ }^{33} \mathrm{AC}, 59-7$. 
inscripción de Mérida, citada en el cuaderno 12 del manuscrito de Carbonel, se puede identificar también con los materiales epigráficos de la Real Academia de la Historia ${ }^{34}$. Según la nota que acompaña a esta inscripción, una copia había sido entregada a Carbonel para que hiciese una ilustración de la misma «para reconocer si puede servir de alguna luz a los sucessos y Historia del tiempo a que pareze referirse [...]» y para realizar un «discurso sobre las utilidades o ventajas que puede conseguir la historia de España, en especial de los tiempos después de su pérdida por medio de los historiadores o escritos árabes; expressión de quáles sean estos, con noticia de si existen impressos o manuscritos o si del todo se han perdido [...]» y un «examen de la misma inscripción y de sus caracteres $[\ldots] \gg$.

Estos son algunos de los temas que explican los materiales misceláneos con los que Campomanes y Carbonel estudiaron árabe. En el siguiente apartado voy a intentar explicar cómo estos materiales se integraban en un método de aprendizaje.

\section{Lenguas vivas y lenguas muertas}

En otro manuscrito de la $\mathrm{BNE}^{35}$, se conservan varios documentos de José Carbonel, muchos de los cuales tienen que ver con su interés por el árabe, el hebreo, el griego y, en general, por el aprendizaje de lenguas. Uno de esos documentos, que aparece en dos versiones, lleva el título de «Informe al Real Consejo de Castilla sobre los medios de hacer florecer en la Universidad de Salamanca el estudio de las lenguas Griega y hebrea. Por Don Joseph Carbonel, de la Real Academia de la Historia, Director de los Reales Estudios de Cádiz y Comisario de Marina. Cádiz y julio 1 de $1768 »{ }^{36}$. En el Archivo de de Campomanes ${ }^{37}$ se encuentra una versión anterior de este documento, titulada «Método de enseñar las lenguas Griega, Hebrea, Caldea y Siriaca». Según una carta de Carbonel a Campomanes fechada en 1767 que acompaña este documento, Carbonel lo había compuesto unos años antes a instancia

${ }^{34}$ Martínez Núñez, Epigrafía árabe, inscripción 15/2, 73-4.

${ }^{35}$ Carbonel, Papeles varios.

${ }^{36}$ Carbonel, Papeles varios, ff. $117 \mathrm{r}$ y $135 \mathrm{r}$

${ }^{37} \mathrm{AC}, 23-35$. 
de Cristóbal de Medina Conde, catedrático de griego en el Sacromonte de Granada. A juzgar por la sucesión temporal de los documentos, se podría deducir que este primer documento dirigido al Sacromonte fue después reformulado y ampliado para configurar un proyecto de reforma de la enseñanza del griego y del hebreo en Salamanca. Habría que señalar, por cierto, que la relación de Carbonel con Medina Conde pronto se tornaría problemática: el canónigo fue un reconocido falsario, implicado en las falsificaciones de la Alcazaba de Granada que dieron lugar a un sonoro proceso y a una sonora polémica, en la que participó Carbonel con críticas a las que Medina Conde intentó responder ${ }^{38}$.

En su proyecto de reforma, Carbonel aborda tres aspectos para impulsar la enseñanza del griego y el hebreo en Salamanca: la elección de maestros por oposición; la perspectiva de premio para los jóvenes estudiosos; y la aplicación de un método de enseñanza «menos fastidioso y más breve», que es la cuestión que me interesa aquí. Para abordarla, Carbonel comienza por dejar asentado que tanto el griego como el hebreo eran «lenguas muertas» y, por lo tanto, su aprendizaje debía estar orientado a la comprensión de textos escritos, y no al habla o a la escritura. En lo tocante a los caracteres y la pronunciación, Carbonel afirma que, así como un estudiante podría aprender rápidamente a leer el griego, el hebreo era más difícil por la singularidad de las letras y el hecho de escribirse de derecha a izquierda, por lo que difícilmente se podría tardar menos de un mes en leer con soltura.

En cuanto a la pronunciación, la del hebreo se podía establecer, en primer lugar, por su semejanza con el siriaco, que aún se mantenía entre algunos maronitas pobres de Monte Líbano que no se habían mezclado con otras naciones ${ }^{39}$, y con el árabe; lenguas ambas antiquísimas y cuya pronunciación se había mantenido inalterada a través de los siglos. Aun cuando los últimos hablantes del siriaco desaparecieran pronto, la pronunciación del hebreo podría reconstruirse gracias al árabe, lengua viva para muchas y poderosas naciones. Es esta

${ }^{38}$ Barrios Aguilera, La invención, p. 402.

39 «Y mi venerado maestro Don Miguel Casiri, de quien tuve la fortuna de aprender los fundamentos del idioma arábigo, me aseguró que después de haber estudiado el syriaco en Roma, logró, en su viage a ese celebrado Monte, conversar con una anciana maronita que no sabía otra lengua que la syriaca, que la entendió perfectamente y no halló diferencia entre su pronunciación y la que le habían enseñado en el Colegio», (Carbonel, Papeles varios, f. 143r). 
una idea que se puede encontrar también en Campomanes, que escribía que: «la pronunciación hebrea se ha de tomar del árabe de cuio alfabeto es unísono ${ }^{40}$, al tiempo que criticaba a los etimologistas que habían propuesto un origen hebreo para varias palabras castellanas, argumentado que el hebreo nunca fue «lengua corriente y viva» en España: muchas de esas palabras eran árabes o comunes a ambas lenguas, y, además, los judíos de Oriente, África y España trasladaban al árabe sus propios escritos, aprovechando la correspondencia entre ambos alfabetos ${ }^{41}$.

Una vez alcanzado el grado de destreza necesario en la lectura, prosigue Carbonel, los estudiantes de griego y hebreo deben pasar a los ejercicios de memoria, y aprender las declinaciones de nombres y adjetivos, los pronombres y las conjugaciones verbales. Éstas deben ser estudiadas «con tanta viveza y esmero que se sepan todas juntas, como dicen, de carretilla, y ayudar a la memoria con la comprensión, haciéndoles dueños de las reglas de conjugar». Luego deben aprenderse los adverbios, preposiciones, conjunciones e interjecciones, con sus equivalentes castellanos, y luego las reglas de la sintaxis, haciéndolo muy deprisa, para que el aprendizaje de unas cosas no haga olvidar otras.

Éste es el momento de pasar a la traducción, según Carbonel, sin abandonar el ejercicio continuado en los regímenes verbales, ajustándose a los principios y elementos generales, hasta que estén asentados. El estudiante debe «nombrar la $1^{\text {a }}$ persona de los tiempos fundamentales de un verbo nuevo o poco obvio, las irregularidades que tuviere, las raíces de las voces compuestas o derivadas y las reglas de syntaxis observadas en la traducción». El maestro explicará las novedades, pero procurará no dar muchas excepciones de golpe para no estorbar la asimilación de los principios generales. Luego, el estudiante copiará en casa todas estas primeras personas y anomalías verbales en dos columnas, una original y otra en castellano, junto con la traducción entera de que fueron extraídas; tarea que debe ser corregida por el profesor delante del resto de los alumnos.

Existían autores y libros propicios para esta traducción. Para el griego, primero Luciano, con el necesario expurgo moral, y luego, para

${ }^{40} \mathrm{AC}, 28-8$.

${ }^{41}$ Campomanes, "Discurso preliminar", p. xxviii. 
que los estudiantes se hagan a la variedad de estilos, obras históricas (Eliano, Herodiano, Plutarco) y poéticas (Homero, Aristófanes, Eurípides, Anacreonte, Píndaro). Pero, al pasar de una obra a otra de distinto estilo, convenía explicar a los estudiantes las reglas de este, y no mezclar la prosa, que debía traducirse por la mañana, con la poesía, por la tarde. En cuanto al hebreo, debía empezarse a traducir el Génesis, y luego los otros libros históricos de la Biblia durante tres o cuatro meses, para continuar con los salmos por la tarde, y luego con Isaías y Oseas. Con cada traducción, los estudiantes deberían repetir mañana y tarde las columnas escritas con las palabras, las raíces y las nuevas reglas de sintaxis aprendidas en la sesión precedente, añadiendo de paso la declinación de un nombre o pronombre, y la conjugación de cuatro o cinco verbos regulares. Y una vez aprendidas las reglas de la sintaxis bastaría repetir una mañana y tarde para no olvidarlas.

En cuanto al vocabulario, los estudiantes debían memorizar continuadamente $10 \mathrm{u} 11$ palabras castellanas con etimologías griegas o hebreas, para aumentar el caudal de voces conocidas gracias a la facilidad de su cercanía al castellano. Sin duda, este consejo de Carbonel puede ayudar a explicar el documento «Etymologías Castellanas y Lemosinas sacadas del Griego y Hebreo», que se encuentra en el cuaderno 5 del manuscrito 11554, y cuyo contenido debía estar orientado a este uso pedagógico. En todo caso, las pruebas de vocabulario debían ser repetidas hasta el final del curso, cada vez más deprisa. Eventualmente, se taparía la columna de palabras hebreas o griegas, y la de sus correspondientes castellanas, para facilitar su memorización, aunque a esta tarea no debía obligarse a nadie.

En cuanto a las composiciones, debían evitarse a los estudiantes normales, a no ser de oraciones simples y de viva voz, para ejercitar conjugaciones, declinaciones y sintaxis; pues tratándose de lenguas muertas, era más importante entender sus textos que escribir o hablar en ellas. Sin embargo, un aspirante a cátedras sí debía hacer composiciones: por ejemplo, eligiendo un texto griego, traduciéndolo, y luego intentando reconstruir el texto original, cotejándolos al final y comprobando los errores; repitiendo toda la operación «con el mismo orden y a intervalos precisos de descanso», hasta reconstruir el texto sin fallos. Este método permitiría tener por maestros de estilo a los grandes escritores del pasado, y tenía la ventaja de poder repetirse sin la presencia del maestro ni ocupar tiempo de sus clases. 
Entre otros consejos sobre la edad en que debía aprenderse el estudio del griego, Carbonel añadía uno para los aspirantes a cátedras: la lectura diaria de textos clásicos, pero no sólo con los ojos, como los castellanos y latinos, sino pronunciándolos en voz alta, para que «entren las especies en la memoria por más de un sentido, y hagan por consiguiente más profunda impresión». El hebreo debía estudiarse después de la filosofía, y podía aprenderse en un solo curso, pues, aparte de la escritura, era más fácil que el griego, y los monumentos literarios conservados en él eran poco variados, con la excepción de Job y el Cantar de los Cantares.

Seguramente, estos principios que da Carbonel para el estudio del griego y del hebreo en Salamanca pueden ayudar a entender el método con el que se utilizaban los materiales árabes de los que he hablado en los apartados anteriores, salvo por un hecho: el árabe es una lengua viva, y no muerta. Obviamente, lo que más diferencia el método de aprendizaje en uno y otro caso son las composiciones y los diálogos. En cuanto a los primeros, ya se ha visto que el estudio especializado de una lengua muerta los requería también, según una cierta regla. Los diálogos, en cambio, no aparecen en este informe porque, por su propia naturaleza práctica, intentan reproducir escenas de la vida real, al menos en teoría. Precisamente a este aspecto voy a dedicar el siguiente apartado.

\section{Los diálogos}

Ya se ha visto cómo los diálogos ocupan una parte no pequeña de los documentos de Campomanes y Carbonel sobre los que estoy escribiendo. Estos diálogos están escritos en árabe y en castellano, y, en este apartado, voy a hacer una presentación parcial de la parte castellana de los mismo, citándola o resumiéndola según las necesidades de la argumentación.

¿Cuál es el contenido de estos diálogos? ¿En qué medida constituyen, también, una mirada antropológica sobre el mundo árabe? En el primero de esos diálogos, y con el tema de los saludos, se introducen dos personajes, uno de los cuáles es local y saluda e interroga a otro que viene de Oriente o de Egipto, y que ha viajado a otra ciudad oriental (¿Beirut?) para «oler el aire» por dos meses. En el segundo diálogo 
se escenifica un «combite para comer», y en él el primer personaje invita a su casa al segundo:

- Mañana es fuerza que me haga la honra de comer conmigo / — No es menester incomodarse / —No hai en esto incomodo / — ¿Qué tiene de bueno? / - Tengo pichones, gallinas, pájaros, fruta y otros regalos / — ¿Quántos géneros de vino tiene? / — 4 géneros, vino de Chipre, de Beqfaia, del Monte Líbano y de Francia $[\ldots]$.

Tras esta evocación de los vinos libaneses como el de Bikfaya, la comida se desarrolla entre cumplidos («- Coma sin ceremonias: haga cuenta que está en su casa; [...] — Dios bendiga las manos de la cocinera»), mientras comen sopa, asado, arroz a la turca, frito (miqlī), y de fruta una manzana, un racimo de uvas, dos higos, una tajada de melón y una pera.

El tercer diálogo se desarrolla durante la sobremesa: los contertulios toman café y fuman en sus pipas (parece que de agua) tabaco de Laodicea. Uno de ellos pregunta cuánto cuestan cinco libras (es decir, un rațl) de ese tabaco, y el otro le contesta que «un real de a ocho» (qirš en árabe). Después de un paseo por la playa, ambos personajes se dirigen a casa de un mercader para pasar allí la noche; ese es el escenario del cuarto diálogo, donde, al decir el mercader que es «del país de los francos», se inicia una conversación sobre las diferencias entre ambas sociedades, europeas y árabes:

- Cuéntanos pues de las propiedades del país de los francos, ya que tenemos tiempo / - Como mande V.M.; hai gran diferencia entre las cosas del país de los francos y del país del Oriente / — ¿Y cuál será esta diferencia? / —Sin duda que el país del Oriente en quanto a las cosas naturales excede al país de los francos. Primeramente en quanto a la perfección del clima y el temperamento de las estaciones. Pues aquí la primavera es perfecta y es verano assí mismo, y el otoño y el imbierno. Pero la región de los europeos es mejor en quanto a las cosas morales, esto es, en las artes, edificios y todas las obras primorosas, el trato y ceremonias, y las cosas de fe y devoción / - Concedo todo esto, pero los que han visitado aquellas regiones felices refieren de sus moradores que son corruptos, y por consiguiente su fee no corresponde a sus acziones / — [...]ne en qué? / — [En q]ue les está permi[ti]da la conversación [y] compañía de [1]as mugeres, de la [qu]al nace toda [cor]ruptela, assí [co]mo nos enseña [la] experiencia cotidiana. Y esto [es]tá concedido por todos. Pues quién es el que no sabe que es impossible [que] la paja se acerque al fuego y no se [q]ueme / — Sepa que la conver[s]ación de las mugeres [e]s de 3 géneros, oficiosa, precisa y amorosa o de $[\mathrm{g}]$ alanteo $[\ldots]$ / — Pero el apartarse y retirarse de las mugeres es más conveniente y útil para quien ama la pureza, especialmente porque semejante conversación es peligrosa según el dicho del 
sabio, que quien ama el peligro perecerá en él / —Sepa que el peligro es de dos géneros, próximo y remoto. El remoto no es pecado, si no nos conviene salir de este mundo, según el dicho del Apóstol. Y el próximo sin duda es pecado, v.g., si el hombre se halla con la muger a solas, conforme juzgó la ley, diciendo que el hombre y la muger a solas no hacen oración [...] / — Verdaderamente tú eres traidor y disimulador de la verdad evidente, porque quieres encubrir las faltas de los Europeos, que en sus países públicamente sin vergüenza y castigo (del juez) usan la corrupción / -De aí conozco que V.M. no conoce el sistema del gobierno y de las leyes de los países de los Christianos, o los que le han informado de esto le han engañado / - No, pues los que me han informado lo vieron con sus propios ojos y lo averiguaron / - Yo juzgo que estos te informaron de lo que han hecho de la corrupción en esos países.

En el cuarto diálogo, breve, uno de los personajes le pide un préstamo al otro, que se lo niega. El quinto diálogo escenifica la conversación entre un doctor musulmán y un doctor cristiano:

—Laus Deo, el qual me concedió la gracia de esta fee ilustre y me adornó con el conocimiento de sus verdades sublimes y ciencias superiores y me ha distinguido de los infieles errantes y faltos de conocimiento; / - Quiero de tu favor, jo sacerdote insigne y doctor de doctores! que tú nos aproveches con tu suave discurso y nos aumentes el conocimiento / — ¿Quién eres tú y de qué país y a dónde llega tu conocimiento? ¿Acaso piensas entender mi discurso sin ciencia y estudio en los libros? / - Yo ya aprendí algo de las ciencias y frequenté las aulas / — ¿Y cómo puede ser esso, quando nosotros sabemos que los Christianos son rudos y carecen de libros y aulas? / - Sepa que en los países de los Francos hai muchas aulas y libros sin número, y hai en ellas [sic] doctores en todo género y especie de ciencias, diré: más que aquí / —Blasphemaste, ¡o señor Sacerdote!, y me parece que tú no has leído en nuestros libros ni has comprehendido sus sublimes sentidos. Y si los hubieras leído, no hablaras con estos términos materiales / - Ya yo leí en vuestros libros, especialmente en el Alcorano y en el poema de Ben Aljariri, y entendí sus sentidos / -Esso no es possible, porque tú eres hombre estrangero en la lengua y no tienes pericia en nuestros libros. Y después de esto hágame saber dónde has aprendido la Rethórica y la Gramática, y quién es tu maestro, y nosotros sabemos que los Francos ignoran esta lengua, como veemos en aquellos que vienen a nuestros países / - Yo ya aprendí esta lengua, no baxo la disciplina de maestro, sino por la lectura de los libros referidos y otros / - Esta cosa es rara y prodigiosa, no puede caber en el entendimiento y no puede creerse. ¿Cómo es posible la adquisición de esta lengua sin maestro, cuando es difícil para muchos el aprenderla con todo el cuidado y voz viva del doctor? / - Este es possible y hecho (con efecto) y la experiencia decide entre yo y tú, y assí cessará todo el pleyto y diferencia / - Luego según tu dicho tú sabes la lengua arábiga, y estás perito en sus sentidos y has exercitado la lectura de nuestros libros, y sobre este supuesto, quiero proponerte algunas preguntas y dudas para que tú me las resuelvas / - Pregunta lo que quieras, io estoi presente, y espero con la ayuda de Dios te satisfaré / - Dime dónde era el hechor de los entes antes de la existencia del lugar, y es cosa entre los impossibles que exista el ente y no exista en lugar, y de otra suerte existiría y no existiría, y esto es absurdo / - Te respondo que antes diremos que Dios verdaderamente 
no está en lugar, sino el lugar en Dios, porque éste contiene y abraza el todo, y no es contenido. Y al contrario sería limitado y coarctado por el lugar si estubiera en él / — ¡Y qué estaba haziendo Dios ab aeterno, antes de la creación del mundo? ¿acaso estava ocioso sin hazer nada? / —Dios en quanto que no pende de sus criaturas y no necessita de ellas y es suficiente en sí mismo por sí mismo y obra en sí mismo, gozoso de sus perfecziones infinitas.

En el diálogo 6, los personajes se dirigen a la orilla del mar para «ver los navíos y los marineros», a un «puerto angosto y poco seguro, porque el viento le predomina, y los navíos están en él con gran peligro. El año passsado se rompió en él un navío francés» y «se anegaron tres almas, y no se salvó nada de la cargazón». Una vez allí, suben a un navío inglés para ver los cañones, y son recibidos por el capitán: «Sean bien venidos, sírvanse sentarse. Muchacho, trae las sillas, trae la fuente de los dulces y la redoma del aguardiente, y échanos de bever».

El séptimo diálogo se produce entre un paisano y un caminante que ha perdido el camino de Jerusalén, y el octavo al alquilar un cuarto por unos meses en un mesón, donde un mercader regatea el precio porque es pobre y no puede anticipar el pago.

En el siguiente diálogo, la breve conversación incluye una alusión al juego, al que es aficionado uno de los contertulios:

- Luego tú eres aficionado al juego. Pero cuida que no te pierda tu tiempo y tu dinero y tu crédito, como sucedió a muchos que conozco / - Yo sé mui bien que el jugar por mera diversión no puede producir tan malos efectos como la réplica de Vuestra Merced insinúa.

En otro diálogo, un personaje pide consejo sobre dónde puede hacerse un traje. Su contertulio le recomienda un sastre en el arrabal de la ciudad, y busca un muchacho para que le acompañe. En principio el muchacho se niega:

-No puedo, estoi ocupado, mi madre no quiere / — ¿Qué se te da de tu madre? Yo se lo diré y te daré estrena / - Iré a llamarle, pero no digas a mi madre nada.

Al final, ya en el sastre, el protagonista pide un traje «que no sea floxo y ancho, sino ajustado a la moda de Constantinopla [...] afórralo con seda (de color) amarillo, y sus bueltas de colorado, y su ruedo de azul». Al final, el sastre le hace el vestido: «—Quítate el vestido y pruébalo. Está como una labor de plata y te viene como una sortija. Disfrútesle con salud. Cíñete sobre él. Ponte derecho. Passea. Levanta el brazo. Arremanga la falda (en la cintura)». 
¿A qué modelos responden estos diálogos? En principio y de manera general, se puede decir que, propuestos como ejercicios con los que aprender los registros adecuados de la lengua en distintas situaciones prácticas, los diálogos forman parte de las técnicas de aprendizaje de una lengua extranjera en Europa desde una época muy antigua. Se trata de una práctica aplicada inicialmente al estudio del latín, popularizada en el s. XVI fundamentalmente gracias a los Colloquia de Erasmo, y que pronto se extendió al estudio de lenguas modernas. En ella se aunaba el aspecto pedagógico, pretendidamente práctico, con una dimensión antropológica, en la medida en que expresan caracteres culturales de las sociedades cuya lengua se está aprendiendo ${ }^{42}$. Dentro de un sistema pedagógico, estos diálogos funcionaban como complemento de las gramáticas y los glosarios ${ }^{43}$.

Así, los papeles de Campomanes y Carbonel, en su diversidad, están replicando ese mismo sistema pedagógico bien establecido ya en la Europa del s. XVI, para el aprendizaje de otras lenguas modernas. Frente al estudio y memorización de normas gramaticales, el diálogo se presenta como una forma de aprender la lengua en el contexto de su realización práctica en situaciones concretas ${ }^{44}$. Sin embargo, estos diálogos no responden exactamente a situaciones reales, sino que tienden a una literaturización que se aleja de lo que hoy entenderíamos son situaciones reales. Por fijarnos sólo en un ejemplo relativo al español, se podrían citar los célebres diálogos de John Minsheu, diseñados para aprender español en Inglaterra, dentro de un método que incluía materiales diversos: gramática, diccionario, selección de textos literarios y sapienciales, diálogos ${ }^{45}$. Se trata éste de un libro en el que participaron seguramente protestantes españoles en Inglaterra, y que influyó finalmente en algunas de las obras más difundidas para la enseñanza del español, como los Diálogos de Cesar Oudin ${ }^{46}$; o la de otro protestante español, los Diálogos familiares de Juan de Luna ${ }^{47}$, que

${ }^{42}$ Lépinette, "Dos diálogos", p. 233.

${ }^{43}$ Lépinette, "Dos diálogos", pp. 189-190.

${ }^{44}$ Castellví y Català, "La fiesta", pp. 675-686.

${ }^{45}$ Para todo esto, Cid, "Leve introducción”. Sobre esta edición, v. también Díaz-Mas, "Vida cotidiana". En general, para este y otros ejemplos, v. el libro clásico de Sánchez Pérez, Historia de la enseñanza, pp. 64ss y passim.

${ }^{46}$ Oudin, Diálogos en español y francés.

${ }^{47}$ Luna, Diálogos familiares. 
acabarían editándose de forma conjunta con los de Minsheu ${ }^{48}$. En la fortuna de estas obras puede advertirse cómo la confluencia de distintos materiales (gramáticas, diálogos, crestomatías) acaba siendo fundamental en la constitución de un canon literario en el que la narrativa picaresca se constituye como un referente fundamental de la recepción de la literatura y la cultura españolas en Europa; en otras palabras, el sistema pedagógico de enseñanza del español ayudó a conformar, en Europa, la figura del pícaro como un elemento reconocible de la cultura nacional.

La comparación entre los diálogos de Carbonel y Campomanes y algunos de los citados muestra inmediatamente semejanzas notables. Por citar el ejemplo de los diálogos de Oudin, diseñados para aprender español en Francia, en ellos aparece la escena del convite, con sus distintos tipos de platos y vinos, seguida de la partida de naipes; un diálogo de cosas «tocantes al camino»; el tema de las diferencias entre los españoles y los ingleses, uno de cuyos argumentos es la relación con las mujeres; más una serie de glosarios temáticos (religión, dignidades temporales, partes del cuerpo humano, vestidos... $)^{49}$. Estos temas eran ya tópicos durante el s. XVII, como muestra el libro de Abel Boyer, The Compleat French-master, obra destinada al aprendizaje del francés en Inglaterra, publicada en 1694 pero que conoció numerosas ediciones durante el s. XVIII. Es un libro, de nuevo, misceláneo, que contiene elementos de gramática, una colección de frases para distintas situaciones, canciones, poemas y cartas en francés, 12 breves diálogos sobre distintos temas, más 40 «diálogos familiares» ${ }^{50}$, que ocurren en distintos tipos de situaciones cotidianas de un caballero o una dama y ponen en uso las expresiones ad hoc: los saludos, el tiempo atmosférico, las horas del día, diálogos entre un caballero o una dama y sus servidores al levantarse y vestirse... y, entre ellos, el diálogo en el paseo, en la visita matinal, entre un caballero y su sastre, durante la comida, sobre cómo aprender francés, alquilar una habitación, comprar un traje, jugar al ajedrez y a las cartas, ir de viaje.

Que este modelo siguió practicándose durante el siglo XVIII puede comprobarse en una obra de 1781, el Arte de hablar bien francés de

${ }^{48}$ Andrés, "Juan de Luna".

${ }^{49}$ Oudin, Diálogos, pp. 50ss, 71, 79ss, 139, 148, 164, 221 ss.

${ }^{50}$ Boyer, The Compleat French-Master, pp. 165ss. 
Pierre Nicolas Chantreau ${ }^{51}$, que contiene una sección sobre «Frases familiares para romper a hablar en Francés», entre los que hay los dedicados a saludarse, «dar lección y hablar francés» («Habla Vmd. francés [...] ¿Con quién da Vmd. lección? [...] ¿Qué libro lee Vmd?»), «Del comer y beber» («La sopa está en la mesa», «¿De dónde es [el vino]? De Champagna, de España?»), «Del paseo», «Del juego en general» («El juego algunas veces es diversión peligrosa. Es verdad, pero cuando se juega a juego fuerte. Aquí no se permite jugar sino juego de amigos»), «Para hablar con un sastre», «Del viage» ${ }^{52}$. Baste añadir aquí que la utilización de diálogos se puede encontrar, también, en manuales de lenguas orientales; como los que incluye Antonio dell'Aquila en su gramática árabe ${ }^{53}$.

De manera que los diálogos de Carbonel y Campomanes pueden ser situados sin problemas en esta tradición de los «diálogos familiares». Por supuesto, existe una gran diferencia entre los diálogos como los de Juan de Luna, donde los caracteres de la supuesta picaresca española se desarrollan por extenso, y los «diálogos familiares» de Chantreau, pequeñas escenas que subrayan los motivos de una cierta educación aristocrática a la francesa. Los diálogos árabes de los que trato aquí se parecen más a estas escenas estandarizadas de Chantreau y su dimensión antropológica es relativamente limitada. El Líbano aparece en detalles, aportados probablemente por Casiri, como los vinos de Monte Líbano y Bikfaya, el tabaco de Latakiya y las pipas de agua, y el tópico de las diferencias culturales aparece aquí reducido a ciertos temas que subrayan la imagen distorsionada que los árabes tienen de los países europeos. Incluso el diálogo entre el doctor cristiano y el musulmán se centra en un asunto, si el mundo es eterno o fue creado, que no forma parte de la lista más habitual de los temas polémicos entre el cristianismo y el islam, sino que remite a una compleja discusión teológico-filosófica medieval ${ }^{54}$. En este material parece prevalecer el aspecto tópico de los diálogos familiares, cuyas reglas genéricas se imponen a la mirada estrictamente antropológica.

\footnotetext{
${ }^{51}$ Lépinette, L'enseignement du français, pp. 93-95.

${ }^{52}$ Chantreau, Arte, pp. 60, 68, 70, 79, 85, 89.

${ }^{53}$ Dell'Aquila, Arabicae linguae, pp. 31 ss.

${ }^{54}$ Herráiz Oliva, "La cuestión De aeternitate mundi"; Saranyana, "La creación 'ab aeterno"”. 


\section{Conclusión}

El título de este artículo, «Cómo aprendió árabe Campomanes», se refiere pues a un proceso con diversas facetas: es en principio una actividad de aprendizaje con los instrumentos gramaticales y lexicográficos árabes producidos por el orientalismo europeo; pero, más que eso, es un proceso polifacético de aprehensión cultural. Como muestran los documentos de Campomanes y Carbonel, la enseñanza de Casiri responde a una tradición orientalista que se acomoda a la estructura habitual de los manuales de aprendizaje de otras lenguas, al incorporar la enseñanza del árabe a un sistema utilizado para aprender lenguas extranjeras desde al menos el s. XVI, y que incluye la memorización de oraciones y fórmulas morales, la selección y traducción de textos literarios, la escenificación de pequeños dramas que formalizan los temas más simples de la diferencia cultural. Así lo muestra el ejemplo de los «diálogos familiares», al que he dedicado una especial atención en este artículo.

Sin embargo, el árabe no es como otras lenguas europeas: quien quería aprender árabe en el s. XVI tenía que enfrentarse a una ausencia casi total de materiales literarios o gramaticales, a una tradición de conocimiento del islam muy precaria, a una gran ignorancia de la literatura árabe. Producir un sistema de aprendizaje del árabe equivalía también a producir un canon de esa literatura, uno de cuyos principales episodios es el de la constitución y valoración de fondos bibliotecarios orientales en Europa: una historia compleja hecha de viajes, circulación de libros, operaciones comerciales, azar o simple piratería. Lo importante es que se trata de un proceso desarrollado a lo largo de una red que conectaba a los europeos interesados en los saberes orientales. Ya hemos visto cómo ese proceso llega a Campomanes a través de las citas de Johann Fabricius o Edward Pococke y sus obras, a través de las cuales se estaba produciendo en Europa un canon de la poesía árabe. Y con él llega también una interrogación sobre la relación histórica de Europa con el Oriente: como se ha visto, los primeros intentos de desciframiento de inscripciones cúficas se encuentran precisamente entre estos papeles de aprendizaje. Aprender árabe era, pues, integrarse en una tradición erudita que acabará dando forma a muchos de los proyectos historiográficos de Campomanes. 


\section{APÉNDICE DOCUMENTAL}

Contenido del ms. de José Carbonel y Fogasa, de Papeles varios de gramática arábiga, BNE, mss. 11554

Cuaderno 1.- Lleva el título de «Elementos de la Grammática Arábiga, por Don Joseph Carbonel y Fogassa, Comisario de Marina, discípulo de Don Miguel Kasir [sic], Syro. Empezó el día $1^{\circ}$ de Junio de 1748». Como en el caso de los Papeles de Campomanes, la primera parte de los apuntes está dedicada a la gramática; aunque en este caso Carbonel lo hace de una forma sistemática y más extensa, en 36 folios que cubren una exposición de la gramática árabe conforme a los apartados canónicos (volveré sobre este asunto más adelante): 1.- las letras arábigas, sus signos y sus reglas (equivalencia fonética, vocales, signos ortograficos — tanwīn, hamza, tašd $\bar{\imath} d . .$. - permutaciones debidas al uso de las letras alif, waw, $\left.y \bar{a}^{\prime}\right) ; 2$.- las partes de la oración, a saber: el nombre (declinación, número, pronombres, numerales...); el verbo (clases - es decir, formas - conjugación de verbos regulares, sordos e irregulares); la letra o dicción (al-haraf), que incluye los adverbios, las preposiciones, las conjunciones y las interjecciones.

A partir del fol. 38, el cuaderno incluye también elementos gramaticales, pero expuestos de manera no sistemática, como apuntes de trabajo, con tachaduras, correcciones, notas marginales..., y que contiene elementos que no están en la primera parte: así, por ejemplo, en el fol. 75 comienza un capítulo titulado «De la sintaxis».

Cuaderno 2.- «Composiciones arábigas. Por el Comisario de Marina Don Joseph Carbonel Fogasa, discípulo de Don Miguel Casiri, presbítero syro, unos $[\mathrm{sic}]$ de los bibliotecarios del Rei nuestro Señor», y después, con otra tinta «En el año de 1748, en compañía de Don Pedro Campomanes, oi (1788) Gobernador Interino del Consejo y Conde de Campomanes». Se trata de composiciones en árabe y latín.

Cuaderno 3.- 22 folios de glosarios con el título «Recopilación de las vozes más usadas en las lenguas castellana y arábiga. Por Don Joseph Carbonel Fogasa, Comisario de Marina. [alia manu] Profesor de lenguas y mathemáticas, Madrid, 1748». En él se incluyen varios glosarios incompletos latin-árabe y castellano-árabe organizados por campos semánticos («Homo»; «corpus»; «astrum»; «regnum»; «rus»; «parentela»; «tempus»; «tratamiento»; «religió»; «vita»; «delictum»; «Metaphisica»; «Quadrupes»). 
Cuaderno 4.- «Apuntaciones sobre la escritura Arábigo-Cúfica», en un único folio.

Cuaderno 5.- «Etymologías Castellanas y Lemosinas sacadas del Griego y Hebreo». En realidad, el título original era «Etymologías Castellanas y Lemosinas sacadas del Griego, Hebreo y Árabe», aunque las dos últimas palabras han sido tachadas, y una nota marginal añade: «N.B.: las voces escritas con caracteres Arábigos son hebreas». En efecto, entre las palabras contenidas en este elenco se encuentran, varias supuestas etimologías hebreas tomadas de la Biblia, pero escritas en árabe. Por ejemplo, para «azote» se propone la etimología « $\langle\bar{s} \bar{u} z »$, «hašūz», tomado de Isaías 28:15; la palabra es hebrea, pero transcrita en caracteres árabes ${ }^{55}$.

Cuaderno 6.- «Coleczión de raíces arábigas selectas» que, como se explica en la segunda página, se trata de una «lista de voces arábigas y castellanas recogidas en la traducción de la parte $5^{\text {a }}$ del libro del Bitar»; es decir, un vocabulario producido en el contexto de la traducción de Ibn al-Bayțār.

Cuaderno 7.- «Diálogos arábigos y castellanos», que reproducen, en árabe y en castellano, supuestas situaciones prácticas de complejidad creciente: así, el primero contiene unas preguntas y respuestas para saludar para iniciar una conversación: «buenos días», «pax tibi», «¿cómo estás?», «¿de qué país vienes?», «supongo que tú ya has aprendido la lengua española», «este país es caro»..., con sus correspondientes respuestas. El segundo diálogo, sobre el «combite», comienza con una invitación («mañana es fuerza que haga la honra de comer conmigo»), y luego reproduce la conversación que se desarrolla sobre la comida. Más adelante, en el mismo cuaderno, se halla una lista de «de algunos dichos morales pertenecientes a la virtud y vicio general».

Cuaderno 8.- «Traduczión de una carta de recomendación dada a uno que va a Alepo», en la que se ilustra cómo debe ser el estilo de una carta de presentación, en árabe y castellano. También se encuentra la ilustración de la fórmula apropiada para dirigirse al Arzobispo de Tiro y Sidón.

Cuaderno 9.- El inicio de la traducción castellana del libro Šams al-ma 'àrif de al-Būn̄̄, con el comentario «Principio de un libro Arábigo

${ }^{55}$ Como simple dato, se podría recordar, por ejemplo, que en el caso de «azote» Covarrubias recoge el étimo árabe, pero él mismo dice preferir el hebreo (Covarrubias, Tesoro, f. 12v). 
que puede dar idea del estilo orgulloso y enfático de los pretendidos sabios de aquella nación».

Cuaderno 10.- Copia de unos fragmentos del Specimen arabicum de Johann Fabricius Dantiscanus (es decir, de Gdansk o Danzig) ${ }^{56}$. Los textos que Carbonel copia del Specimen arabicum son: la maqāma primera de al-Harīin̄, una casida de Abū l- 'Alā' al- Ma arrī, y otra de del místico egipcio Ibn al-Fāriḍ (aquí llamado erróneamente Ibn Farid, como en el original). Cabe señalar que en el original, Johann Fabricius había completado su texto con notas gramaticales, ausentes en el manuscrito de Carbonel. Además, en el Specimen, la traducción latina es interlineal palabra por palabra; en el manuscrito de Carbonel, sin embargo, éste ha colocado la traducción latina como un texto corrido.

Cuaderno 11.- «Papeles varios de gramática arábiga», con diversas anotaciones gramaticales: modos verbales; una equivalencia de los alfabetos árabe y samaritano; oraciones cristianas (Ave María, Símbolo de la Fe, Padre Nuestro...), de algunas de las cuales se dice que son «Preces christianorum more orientalium»; fórmulas de cumplimiento; fórmulas religiosas de los coptos, y copia de un fragmento de una epístola de Claude Saumaise a Nicolas Fabri de Peiresc sobre fórmulas religiosas de los $\operatorname{coptos}^{57}$; una página de un libro impreso, que no he logrado identificar, con el texto hebreo y la traducción inglesa del «Adon Olam Asher Malach», tratando de la liturgia judía; un texto mágico árabe; los nombres de los meses del calendario gregoriano en árabe; la reproducción y comentarios sobre inscripciones árabes, entre ellas la de un cañón capturado en Lepanto.

Cuaderno 12.- Reproducción de una inscripción árabe de Mérida, con traducción y comentarios a cargo de Casiri. Según una nota que la acompaña, una copia había sido entregada a Carbonel «para reconocer si puede servir de alguna luz a los sucessos y Historia del tiempo a que pareze referirse $[\ldots] »$; realizar un «discurso sobre las utilidades o ventajas que puede conseguir la historia de España, en especial de los tiempos después de su pérdida por medio de los historiadores o escritos árabes; expressión de quáles sean estos, con noticia de si existen impressos o manuscritos o si del todo se han perdido [...]; y un «examen de la misma inscripción y de sus caracteres $[\ldots] \gg$.

${ }^{56}$ Fabricius Dantiscanus, Johann (1638), Specimen arabicum.

${ }^{57}$ Fabri de Peiresc, "Epistola XXXIII", pp. 72-73. 


\section{Bibliografía}

Andrés, Gabriel, "Juan de Luna, el papel de la imprenta y sus textos didácticofamiliares: Coloquio y Diálogos familiares", Rilce. Revista de Filología Hispánica, 31, 1 (2015), pp. 5-21.

Archivo de Campomanes, Fundación Universitaria Española (AC).

Barrios Aguilera, Manuel, La invención de los Libros Plúmbeos. Fraude, historia y mito, Granada, Universidad de Granada, 2011.

Boyer, Abel, The Compleat French-Master, for Ladies and Gentlemen, London, Salusbury, 1694.

Cañes, Francisco, Diccionario español latino-arábigo: en que siguiendo el diccionario abreviado de la Academia se ponen las correspondencias latinas y arabes para facilitar el estudio de la lengua arábiga à los misioneros y à los que viajaren ó contratan en Africa y Levante, Madrid, Antonio Sancha, 1787.

Cañes, Francisco, Gramática arábigo-española, vulgar, y literal, con un diccionario arábigo-espanol, en que se ponen las voces más usuales para una conversacion familiar, con el texto de la Doctrina Cristiana en el idioma arabigo, Madrid, Antonio Pérez de Soto, 1776.

Carbonel y Fogasa, José, Papeles varios, BNE mss. 11552.

Carbonel y Fogasa, José, Papeles varios de gramática arábiga, BNE, mss. 11554.

Carrillo, Juan L. y Torres, María Paz, Ibn al-Baytar y el arabismo español del XVIII. Edición Trilingüe del prólogo de su "Kitab al-chami”, Benalmádena, Ayuntamiento, 1982.

Casiri, Miguel, Bibliotheca arabico-hispana escurialensis sive Librorum omnium Mss. quos arabice ab auctoribus magnam partem arabo-hispanis compositos Bibliotheca Coenobii Escurialensis complectitur recensio \& explanatio, Madrid, Antonius Perez de Soto, 1760-1770, 2 vols; ed. lit. Osnabrück, Biblio Verlag, 1969.

Castellví, José María y Català, Dolors, "La fiesta en las gramáticas de lengua francesa para españoles (finales del siglo XVIII-principios del siglo XIX)", en E. Real, D. Jiménez, D. Pujante y A. Cortijo (eds.), Écrire, traduire et représenter la fête, Valencia, Universitat de València, 2001, pp. 675-686.

Chantreau, Pierre Nicolas, Arte de hablar bien francés o gramática completa, Madrid, Antonio de Sancha, 1781.

Cid, Jesús Antonio, "Leve introducción a unos diálogos hispano-ingleses", en John Minsheu, Diálogos. Pleasant and Delightful Dialogues, ed. Jesús Antonio Cid, Instituto Cervantes, [en línea], disponible en: $<$ https://cvc.cervantes. es/literatura/clasicos/dialogos_minsheu/introduccion/default.htm $>$ [consultado el 19 de febrero de 2019].

Clarke, Samuel, Scientia metrica et rhytmica, seu Tractatus de prosodia arabica, ex authoribus probatissimis eruta, Oxford, excudebat H.H. Academiae Typographus, 1661. 
Covarrubias, Sebastián de, Tesoro de la lengua Castellana o española, Madrid, Luis Sánchez, 1611.

dell'Aquila, Antonio, Arabicae linguae novae et methodicae institutiones, Roma, 1650.

Díaz-Mas, Paloma, "Vida cotidiana y literatura oral en diálogos humanistas para el aprendizaje de lenguas vulgares", Revista de Dialectología y Tradiciones Populares, 58, 2 (2003), pp. 237-248.

Die Maculet, Rosario y Alberola Romá, Armando, “José Carbonel Fougasse (1707-1801). El rastro de un erudito en la España ilustrada", Revista de Historia Moderna, 28 (2010), pp. 11-50.

Fabri de Peiresc, Nicolas, "Epistola XXXIII a Monsieur Peiresc", en Antonio Clementio, Claudii Salmasii viri maximi Epistolarum liber primus, Lugduni Batavorum, ex Tipographia Adriani Wyngaerden, 1656.

Fabricius Dantiscanus, Johann, Specimen arabicum quo exhibentur aliquot scripta arabica, partim in prosa partim ligata oratione composita [...], Rostock, Haeredum Richielianorum Typis expressa, 1638.

Fernández, Paz, "Arabismo español del s. XVIII: origen de una quimera”, Cuadernos de la Biblioteca Islámica "Félix María Pareja”, 1991.

Gallien, Claire, "Orientalist Pococke. Brokering across Borders, Disciplines, and Genres", en Robert Mankin (ed.), The Internationalization of Intellectual Exchange in a Globalizing Europe, 1636-1780, Lewisburg, Bucknell University Press, 2018, pp. 1-31.

García-Arenal, Mercedes y Rodríguez Mediano, Fernando, "Los libros de los moriscos y los eruditos orientales", Al-Qanțara, 31 (2010), pp. 611-646.

Gil Fernández, Luis, Campomanes. Un helenista en el poder, Madrid, Fundación Universitaria Española, 1976.

Girard, Aurélien, "Les manuels de langue arabe en usage en France à la fin de l'Ancien Régime", en Manuels d'arabe d'hier et d'aujourd'hui: France et Maghreb, XIX ${ }^{e}-X X I^{e}$ siècle, París, Éditions de la Bibliothèque Nationale de France, 2013, [en línea], disponible en: <http://books.openedition.org/ editionsbnf/259> [consultado el 26 de febrero de 2019].

Golius, Jacobus, Arabicae Linguae Tyrocinium, id est Thomae Erpenii Grammatica Arabica cum varia praxios materia cujus elenchum versa dabit pagella, Lugduni Batavorum, Typis \& impensis Ioannis Maire, 1656.

Herráiz Oliva, Pilar, "La cuestión De aeternitate mundi en Averroes y los averroístas”, Humanidades: Revista de la Universidad de Montevideo, 1 (2017), pp. 51-71.

Holt, Peter Malcolm, “An Oxford Arabist: Edward Pococke”, Studies in the History of the Near East, Londres, Frank Cass, 1973, pp. 3-26.

Ibn al-'Awwām, Yahyyà, Libro de Agricultura, su autor el doctor excelente Abu Zakariya Iahia Aben Mohamed Ben Ahmed Ebn El Awam, sevillano [Kitāb al-filāha mu'allifu-hu al-šayj al-fādil Abū Zakariyya Yahya [sic] b. Muham- 
mad b. Aḥmad Ibn al- 'Awwām al-Išbīlī], ed. José Antonio Banqueri, Madrid, Imprenta Real, 1802; ed. facsímil con "Estudio preliminar y notas" de J. Esteban Fernández Bermejo y Expiración García Sánchez, Madrid, Ministerio de Agricultura, 1988.

Labarta, Ana, "Banqueri y un anillo árabe. Lectura de una impronta del siglo XVIII", Revista del CEHGR, 27 (2015), pp. 79-95.

Ladero Quesada, Miguel Ángel, "Campomanes medievalista”, en Gonzalo Anes y Álvarez de Castrillón (coord.), Campomanes en su II Centenario, Madrid, Real Academia de la Historia, 2003, pp. 35-116.

Lépinette, Brigitte, "Dos diálogos franco españoles: Liaño 1565 y Oudin 1604", en El francés y el español en contraste y en contacto (siglos XV-XVII), Valencia, Universitat de València, 2001, pp. 189-237.

Lépinette, Brigitte, L'enseignement du français en Espagne au XVIII siècle dans ses grammaires. Contexte historique. Concepts linguistiques et pédagogie, Münster, Nodus Publikationen, 2000.

Loop, Jan, “Arabic Poetry as Teaching Material in Early Modern Grammars and Textbooks", en J. Loop, A. Hamilton y Ch. Burnett (eds.), The Teaching and Learning of Arabic in Early Modern Europe, Leiden-Boston, Brill, 2017, pp. 30-251.

Loop, Jan, Johann Heinrich Hottinger. Arabic and Islamic Studies in the Seventeenth Century, Oxford, Oxford University Pres, 2013.

Lourido, Ramón, "Estudio preliminar" a Bernardino González, Intérprete arábico. Epítome de la gramática arábica, ed. lit., Real Academia de la Historia, 2005.

Luna, Juan de, Diálogos familiares, en los quales se contienen los discursos, modos de hablar, proverbios y palabras españolas más comunes. Muy útiles y provechosas para los que quieren aprender la lengua castellana, París, en la tienda de Samuel Thiboust, en el Palacio, en la galería de los prisioneros, 1621.

Martín Escudero, Fátima, Las monedas de al-Andalus. De actividad ilustrada a disciplina científica, Madrid, Real Academia de la Historia, 2010.

Martín Escudero, Fátima, "El primer proyecto de publicación de un catálogo de moneda andalusí en España: Discurso y Tablas de medallas árabes de Miguel Casiri", Documenta \& Instrumenta, 8 (2010), pp. 145-180.

Martínez Núñez, María Antonia (con la colaboración de Isabel Rodríguez Casanova y Alberto Canto García), Epigrafía árabe. Catálogo del Gabinete de Antigüedades, Madrid, Real Academia de la Historia, 2007.

Moscoso, Francisco, "El siglo XVIII español y el estudio del árabe. El árabe dialectal en la Gramática del Padre Cañes", Revista de Estudios Internacionales Mediterráneos, 22 (2017), pp. 165-186.

Oudin, Cesar, Diálogos en español y francés. Dialogues en François \& Espagnol, Bruxelles, François Foppens, 1604.

Pérez Bayer, Francisco, "Carta a Gregorio Mayáns", Valencia, 29 de diciembre de 1745, Biblioteca Valenciana Digital, [en línea], disponible en: 
$<$ http://bv2.gva.es/i18n/corpus/unidad.cmd?idCorpus=20000\&idUnidad=494 73\&posicion $=1>$ [consultado 26 de febrero de 2019].

Rodríguez Campomanes, Pedro, "Discurso Preliminar sobre la utilidad de la lengua arábiga", en Cañes (1787), pp. vii-xxxv.

Rodríguez Mediano, Fernando, "El perfil intelectual de un arabista ilustrado español: José Carbonel y Fogasa", eHumanista, 43 (2019), pp. 30-44.

Sánchez Pérez, Aquilino, Historia de la enseñanza del español como lengua extranjera, Madrid, Sociedad General Española de Librería, S.A., 1992.

Saranyana, Josep-Ignasi, “La creación 'ab aeterno'. Controversia de Santo Tomás y Ramón Martí con San Buenaventura”, Aquinate, 3 (2006), pp. 87-110.

Soto, José Luis, Arabismo e ilustración. Correspondencia literaria (1791-1803) de Fr. José Antonio Banqueri con Don Fr. Manuel del Cenáculo Vilas Boas, obispo de Beja y arzobispo de Évora, Oviedo, Universidad de Oviedo, 1985.

al-Ṭugrā' 1 , Hasan, Lāmiyyat al- 'aŷam. Lamiato'lAjam. Carmen Tograi, poetae arabis doctissimi, Oxford, ed. Edward Pococke, apud Ric. Davis Bibliopolam, excudit Hen. Hall, Arabicis Aca., 1661.

Zwartjes, Otto, "Inflection and Government in Arabic according to Spanish Missionary Grammarians from Damascus (XVIIIth Century): Grammars at the Crossroads of two Systems?", en Everhard Ditters y Harald Motzki (eds.), Approaches to Arabic Linguistics, Presented to Kees Versteegh on the Occasion of his Sixtieth Birthday, Leiden-Boston, Brill, 2007, pp. 209-244.

Zwartjies, Otto, "Métodos de enseñanza y aprendizaje de lenguas en la Nueva España: el Colegio de Tlatelolco", en Esther Hernández y Pilar Máynez (eds.), El Colegio de Tlatelolco. Síntesis de historias, lenguas y culturas, México, Destiempo, 2016, pp. 174-203.

Recibido: $07 / 04 / 2020$

Aceptado: 09/07/2020 